\title{
5-Aminolevulinic acid photoactivated over planktonic and biofilm forms of Enterococcus faecalis as a pharmacological therapy alternative
}

\author{
Adriana Beltran-Leal', Abraham Muñoz-Ruiz², Vicente Esparza-Villalpando², \\ Yolanda Castro ${ }^{1}$, Amaury Pozos-Guillen ${ }^{\circledR 3}$, Héctor Flores ${ }^{3, *}$ \\ ${ }^{1}$ Faculty of Dentistry, Sinaloa University, Culiacan, Sin., Mexico, ${ }^{2}$ Materials Engineering \\ and Science Doctorate Program, San Luis Potosi University, México, ${ }^{3}$ Basic Sciences \\ Laboratory, Faculty of Dentistry, San Luis Potosi University, México
}

\begin{abstract}
The purpose of the study was to evaluate the antibacterial effect of protoporphyrin IX (PpIX) generated by the exogenous administration of 5-aminolevulinic acid or $\delta$-ALA and activated with an argon laser over a planktonic and biofilm of Enterococcus faecalis (E. faecalis) as a pharmacological therapy alternative. A planktonic strain of E. faecalis was cultured with a solution of $\partial$-ALA (40 $\mu \mathrm{g} / \mathrm{mL}$ )-thioglycolate solution for $13 \mathrm{~min}$, and a biofilm of E. faecalis was cultured in a $\delta$-ALA (80 $\mu \mathrm{g} / \mathrm{mL}$ )-thioglycolate solution for $13 \mathrm{~min}$. Then, both were irradiated with an argon laser. Finally, the antibacterial effect was evaluated by counting the CFU in planktonic form, and a LIVE/DEAD viability cell test. The production and accumulation of PpIX from exogenously administered $\delta$-ALA on E. faecalis in planktonic and biofilm forms was confirmed by spectrofluorometry. The irradiation of PpIX with an argon laser produced an antibacterial effect on E. faecalis in planktonic and biofilm form, even without biofilm disruption, at a concentration of $40 \mu \mathrm{g} / \mathrm{mL}$ and $80 \mu \mathrm{g} / \mathrm{mL}$ of $\delta$-ALA, respectively. The exogenous administration of $\delta$-ALA in combination with laser irradiation on planktonic and biofilm forms of $E$. faecalis produces an effective antibacterial effect as complement or alternative to pharmacological therapies.
\end{abstract}

Keywords: Biofilm. Photodynamic therapy. 5-aminolevulinic acid.

\section{INTRODUCTION}

Microbial infection remains among the leading causes of death worldwide (Barra et al., 2015). Enterococci, important healthcare-associated pathogens, cause serious and often life-threatening diseases. The variety of infections produced by Enterococci include urinary tract infections, intra-abdominal infections, pelvic infections (Gilmore et al., 2014), deviceassociated infections (Darouiche, 2001), soft tissue infections, bacteremia and endocarditis (Gilmore et al., 2014).

*Correspondence: H. Flores, Basic Sciences Laboratory, Faculty of Dentistry, San Luis Potosi University, Av. Dr. Manuel Nava \# 2, Zona Universitaria, C.P. 78290, San Luis Potosi S.L.P, México. Phone number: +52444826235 X 5134. Email: heflores@uaslp.mx
Pathogenic bacteria, such as Enterococci, can attach to biotic or abiotic surfaces (Balcázar, Subirats, Borrego, 2015), forming a microbial community (Donlan, 2011; Li et al., 2013) in a three-dimensional extracellular polysaccharide matrix (EPM) (Balcázar, Subirats, Borrego, 2015; Barra et al., 2015; Li et al., 2013; López-Jiménez et al., 2015) known as a biofilm (Balcázar, Subirats, Borrego, 2015). Additionally, some pathogenic bacteria can develop multidrug resistance due the abuse and incorrect use of pharmacological therapies (Barra et al., 2015).

Microorganisms in a biofilm are exposed to very different environmental conditions from those in planktonic form (López-Jiménez et al., 2015) and many species can change their metabolism depending on the surrounding physiological and physicochemical 
conditions (Balcázar, Subirats, Borrego, 2015). One of the most important characteristics of biofilms is that the microorganisms in it are more resistant to pharmacological therapies as antimicrobials (Balcázar, Subirats, Borrego, 2015; Donlan, 2011; López-Jiménez et al., 2015) (up to 1000 time less susceptibility to specific antimicrobials) (Balcázar, Subirats, Borrego, 2015; Donelli, 2014; Li et al., 2013) and to the host immune defenses compared to their planktonic counterparts ( $\mathrm{Li}$ et al., 2013), mainly because of the protection conferred by the EPM (Balcázar, Subirats, Borrego, 2015).

Mechanical disruption and pharmacological therapies are the most used methods to treat biofilms. However, the efficacy of these strategies is limited because of the persistence of biofilm and microorganisms after mechanical disruption and the appearance of antibiotic resistant strains (López-Jiménez et al., 2015; Rajesh et al., 2011). Moreover, it was reported that the drug levels necessary to kill dispersed bacteria may be ineffective against biofilm associated bacteria (Donlan, 2011).

Photodynamic therapy (PDT) or photodynamic inactivation (PDI) is a clinical procedure that has been emerged as a non-invasive therapeutic modality for the treatment of infections (Dai et al., 2012; Rajesh et al., 2011; Sperandio, Huang, Hamblin, 2013). PDT was first reported by Dobson and Wilson (1992), and they suggest that photosensitization may be effective for eliminating periodontal pathogenic bacteria from dental plaque (Dobson, Wilson, 1992). This technique involves three components: a source of light, a photosensitizer agent (PS) and oxygen (Rajesh et al., 2011). One of the main advantages of PDT is the high target specificity because the PS is localized into the microorganisms without the major involvement of surrounding tissues or cells (Donelli, 2014). Additionally, with PDT, it is possible to avoid the appearance of undesired drug resistant strains (Sperandio, Huang, Hamblin, 2013).

The action of PDT is related to the activation of PS by light of a specific wavelength (Breskey et al., 2013; Pagonis et al., 2010; Rajesh et al., 2011; Soukos et al., 2006) in a non-thermal oxygen-dependent photochemical reaction (Rajesh et al., 2011; Sperandio, Huang, Hamblin, 2013), in which the PS undergo a transition from a low energy state to an excited state (triple state) (Homayoni et al., 2015; Sperandio, Huang, Hamblin, 2013). The triplet state photosensitizer can react with biomolecules by two main photochemical mechanisms called type I and type II (Rajesh et al., 2011; Sperandio, Huang, Hamblin, 2013), by electron transfer or by energy transfer processes, respectively (Sperandio, Huang, Hamblin, 2013). The type I pathway forms superoxide anions that lead to the formation of reactive oxygen species (ROS), such as hydroxyl radicals, whereas the type II pathway leads to singlet oxygen production (Homayoni et al., 2015; Sperandio, Huang, Hamblin, 2013). Both processes produce a cytotoxic effect on bacteria (López-Jiménez et al., 2015; Pagonis et al., 2010).

The PS plays a key role in the efficacy of PDT because it should have specific characteristics for clinical use (Homayoni et al., 2015), such as the presence of absorption bands in the optical window in the red portion of the electromagnetic spectrum $(600-900 \mathrm{~nm})$ when deep light penetration is required (Sperandio, Huang, Hamblin, 2013; Wachowska et al., 2011). The PS should also have a high yield of the excited electronic triplet state and singlet oxygen (Sperandio, Huang, Hamblin, 2013). It should be selectively accumulated in host cells (Barra et al., 2015), and should generate reactive oxygen species in the presence of light and oxygen (Sperandio, Huang, Hamblin, 2013). Furthermore, the PS should have low toxicity without light exposure and possess a relatively rapid clearance from normal tissues to minimize side effects (Breskey et al., 2013; Wachowska et al., 2011). Most PS agents cannot meet all these criteria; therefore, the final selection of the PS depends upon maintaining a balance between optimal photoreactivity and biological properties, which when combined with light irradiation, offers the most effective outcome with the lowest level of side effects (Breskey et al., 2013).

Porphyrin based photosensitizer agents have been approved clinically in the United States for PDT (Homayoni et al., 2015), and one of the most studied is protoporphyrin IX (PpIX) due to its properties. Unfortunately, it has some issues for clinical applications, such as hydrophobicity and low solubility in aqueous solutions (Homayoni et al., 2015), making it useless for deep tissues. By contrast, 5-aminolevulinic acid (5ALA) or delta-aminolevulinic acid ( $\delta$-ALA), a natural amino acid (Hino et al., 2013) and an early intermediate in the heme biosynthesis pathway (Wachowska et al., 2011), although not a PS per se (Barra et al., 2015), is the precursor of the photosensitizer PpIX (Hino et al., 2013; Li et al., 2013). $\delta$-ALA was used for photodynamic therapy for the first time in 1987 for the selective 
elimination of erythroleukaemic cells (Malik, Lugaci, 1987), which opened the possibility of a new approach for cell and bacteria therapy due to its properties of low lipid solubility and reduced bioavailability (Wachowska et al., 2011) but good solubility in water (Li et al., 2013). Moreover, when $\delta$-ALA is taken up by target cells (bacteria), $\delta$-ALA is metabolically transformed to PpIX (Barra et al., 2015). Furthermore, the accumulation of porphyrins is more pronounced in cells with high rates of metabolic activity, such as cancer cells, inflammatory cells and bacteria, resulting in high selectivity (Fotinos et al., 2008).

The aim of the present study was to determinate the antibacterial effect of the exogenous administration of $\delta$-ALA to produce intracellular PpIX irradiated with an argon laser $\left(500 \mathrm{~mW}, 510 \mathrm{~nm}, 200 \mathrm{~J} / \mathrm{cm}^{2}\right)$ on planktonic and biofilm forms of $E$. faecalis.

\section{MATERIAL AND METHODS}

\section{D-ALA solution}

Previous to the experimental work, the minimal inhibitory test was performed to determinate the effective dose of the $\partial$-ALA solution in combination with laser irradiation. For planktonic bacteria, $40 \mu \mathrm{g} / \mathrm{mL}$ was the required dose to obtain an antibacterial effect and a dose of $80 \mu \mathrm{g} / \mathrm{mL}$ was necessary for an effective antibacterial effect on biofilm.

The $\partial$-ALA $(40 \mu \mathrm{g} / \mathrm{mL})$-thioglycolate and $\partial$-ALA $(80 \mu \mathrm{g} / \mathrm{mL}$ )-thioglycolate solution (synthesized in the Environmental Cytopathology Laboratory, IPN, Mexico) were prepared, both enriched with vitamin K. Because it was reported that $\partial$-ALA production is significantly enhanced when the $\mathrm{pH}$ is maintained at neutral range (Sasaki et al., 1993), the $\mathrm{pH}$ of the thioglycolate solution was adjusted to 6.8-7.0 using $\mathrm{NaOH} 10 \mathrm{~N}$.

\section{Isolation of the strain and bacterial cell culture}

An Enterococcus faecalis strain was isolated from teeth with endodontic treatment failure and a periapical lesion, according to the protocol described by Manzur (2007). To confirm isolation of the strain, the API System (BIOMÉRIEUX, USA) was used. The bacteria were cultured in $5 \mathrm{~mL}$ Falcon tubes with continuous shaking at $37^{\circ} \mathrm{C}$ overnight. To determinate the bacterial amount, the optical density (OD) was adjusted to 1.0 , which corresponds to approximately to $5 \times 10^{7}$ cells $/ \mathrm{mL}$.

\section{D-ALA metabolism to PpIX into bacteria}

To determine the production of PpIX after $\partial$-ALA administration, an aliquot of $E$. faecalis was incubated (Incubator Precision Thermo Electron Corporation, USA) with $2 \mathrm{~mL}$ of $\partial$-ALA ( $40 \mu \mathrm{g} / \mathrm{mL})$-thioglycolate solution with continuous shaking for $13 \mathrm{~min}$ at $37{ }^{\circ} \mathrm{C}$. After the incubation, the sample was centrifuged (Centra CL2 Centrifuge, Thermo Electron Corporation, USA) at 5,000 RPM for $10 \mathrm{~min}$. The supernatant was removed, the cell pellets were washed with $1 \mathrm{~mL}$ of PBS, and the samples were centrifuged again at 5,000 RPM for $5 \mathrm{~min}$. Then, the supernatant was removed, and 1 $\mathrm{mL}$ of a lysis solution (ethanol + dimethyl sulfoxide + acetic acid 80:20:1 V/V/V) was added to the samples that were then sonicated for 5 cycles for $5 \mathrm{sec}$. Next, the samples were centrifuged at 5,000 RPM for $3 \mathrm{~min}$. Finally, the supernatant was transferred to a quartz cuvette and read with a spectrofluorometer (PTI Photon International Mod. 5020, USA). The measurements were recorded at $375 \mathrm{~nm}$ excitation with a wavelength range from 300 to $700 \mathrm{~nm}$. All experiments were performed for triplicate.

\section{Photosensibilitation PpIX determination}

After the fluorescence of PpIX was identified by spectrofluorometry at $480 \mathrm{~nm}$, the samples were irradiated with an argon laser type B, $500 \mathrm{~mW}$ (Leica Microsystems $\mathrm{GmbH}$, Mannheim, Germany) at 510 nm (LEICA Acousto Optical Tunable Filter enable to tune the WL) for $8 \mathrm{~min}, 33 \mathrm{sec}$ to reach $200 \mathrm{~J} / \mathrm{cm}^{2}$ (Dosage calculation, power/beam area $\mathrm{x}$ time $=\mathrm{J} / \mathrm{cm}^{2}$ ). Then, the samples were read by spectrofluorometry. The intensity of the fluorescence signal before and after laser irradiation was compared to determinate the photoactivation of PpIX.

\section{Antibacterial effect of PpIX on planktonic E. faecalis}

To evaluate the antibacterial effect on bacterial cells, $2 \mathrm{~mL}$ of culture medium $\left(5 \times 10^{7}\right.$ cells $\left./ \mathrm{mL}\right)$ were treated as follows: group 1 (G1), a positive control group treated with $800 \mu \mathrm{L}$ of thioglycolate $+200 \mu \mathrm{L}$ of sodium hypochlorite $(\mathrm{NaOCl})$ at $5.25 \%$; group $2(\mathrm{G} 2), 1 \mathrm{~mL}$ of thioglycolate + laser irradiation $(8 \mathrm{~min}, 33 \mathrm{sec}$ ); group 3 (G3), $1 \mathrm{~mL} \delta$-ALA $(40 \mu \mathrm{g} / \mathrm{mL})$-thioglycolate solution (control groups); and group $4(\mathrm{G} 4), 1 \mathrm{~mL}$ of $\delta$-ALA (40 $\mu \mathrm{g} / \mathrm{mL})$-thioglycolate solution + laser irradiation for 8 
min, $33 \mathrm{sec}$ as the experimental group. Because there is previous evidence that there is not a significance difference between cultures treated only with laser irradiation or only $\delta$-ALA, these groups were treated as negative control groups. A bacterial cell culture (extension technique) of each group was performed with a dilution of 1:10,000. Then, a CFU count of each group was performed at 0,24 and $72 \mathrm{~h}$.

\section{Determination of the antibacterial effect of PpIX on E. faecalis biofilm}

The formation of biofilm was performed following the protocols previously described by Kaplan et al. (2004), Djordjevic, Wiedmann and McLandsborough (2002) and Zaw Yuthika, Lakshman (2007). On a 24 well microplate with coverslips, $71 \mu \mathrm{L}$ of the inoculum of $E$. faecalis $\left(5 \times 10^{7}\right.$ cell $\left./ \mathrm{mL}\right)$ and $929 \mu \mathrm{L}$ of $3 \%$ thioglycolate enriched with vitamin $\mathrm{K}$ were added. The samples were incubated for 10 days at $37^{\circ} \mathrm{C}$ with continuous shaking. The medium was replaced every $24 \mathrm{hrs}$.

After, the biofilm samples were divided in 4 groups: group "a" (GA), a positive control group treated with 800 $\mu \mathrm{L}$ of thioglycolate $+200 \mu \mathrm{L}$ of $\mathrm{NaOCl} 5.25 \%$; group "b" (GB), $1 \mathrm{~mL}$ of thioglycolate + laser irradiation (8 min, $33 \mathrm{sec})$; group "c" (GC), $1 \mathrm{~mL} \delta$-ALA ( $80 \mu \mathrm{g} / \mathrm{mL})$ thioglycolate solution; and group "d" (GD), $1 \mathrm{~mL}$ of $\delta$-ALA $(80 \mu \mathrm{g} / \mathrm{mL})$-thioglycolate solution $\left(5 \times 10^{7}\right.$ cells/ $\mathrm{mL})+$ laser irradiation to reach $200 \mathrm{~J} / \mathrm{cm}^{2}$.

To determinate the bacteria viability, a LIVE/ DEAD Bacterial Viability Kit was used (Thermo Fisher Scientific, USA). Briefly, the culture medium from each well was removed with a Pasteur pipette to eliminate the non-adherent cells. Then, coverslips were placed in a new multiwall polystyrene plate under sterile conditions, and the biofilm was treated with 200 $\mu \mathrm{L}$ of CTC (5-cyano-2,3 ditolyl tetrazolium chloride) to indicate the cellular respiratory activity. All samples were incubated for $12 \mathrm{~h}$ at $37^{\circ} \mathrm{C}$, with continuous shaking. Then, $200 \mu \mathrm{L}$ of CTC was removed and washed with $1 \mathrm{~mL}$ of $1 \mathrm{X}$ PBS. The biofilm was covered with $200 \mu \mathrm{L}$ of propidium iodide (PI), a fluorescent molecule impermeable to the cellular membrane and generally excluded from viable cells. Finally, the sample was placed on a glass slide and examined on an inverted TCS-SPE confocal microscope (DMI4000B, Leica Microsystems GmbH, Mannheim, Germany). The window of emission ranged from 500 to $520 \mathrm{~nm}$ for the PI and an excitation of $488 \mathrm{~nm}$ for the flow cytometer laser and a window emission range of 600 to $630 \mathrm{~nm}$ for the CTC. This information allows the analysis of the bacterial metabolism because cells in the log phase emit red fluorescence and those in the stationary phase emit green fluorescence.

\section{Data analysis}

Descriptive analysis of the data, a multi-level analysis, ANOVA and post-hoc test (HSD Tukey) were performed to compare the groups with a $95 \%$ level of confidence. Data were analyzed using $\mathrm{R}$ software version 3.2.2.

\section{RESULTS}

\section{Metabolism of $\partial$-ALA to PpIX into bacteria}

The spectrofluorometer test (excitation of $375 \mathrm{~nm}$ ) confirms the presence of PpIX with a wavelength of $480 \mathrm{~nm}$ and an intensity of $1.30 \times 10^{5}$, demonstrating that PpIX was produced by E. faecalis after exogenous administration of $\delta$-ALA (Figure 1, red line).

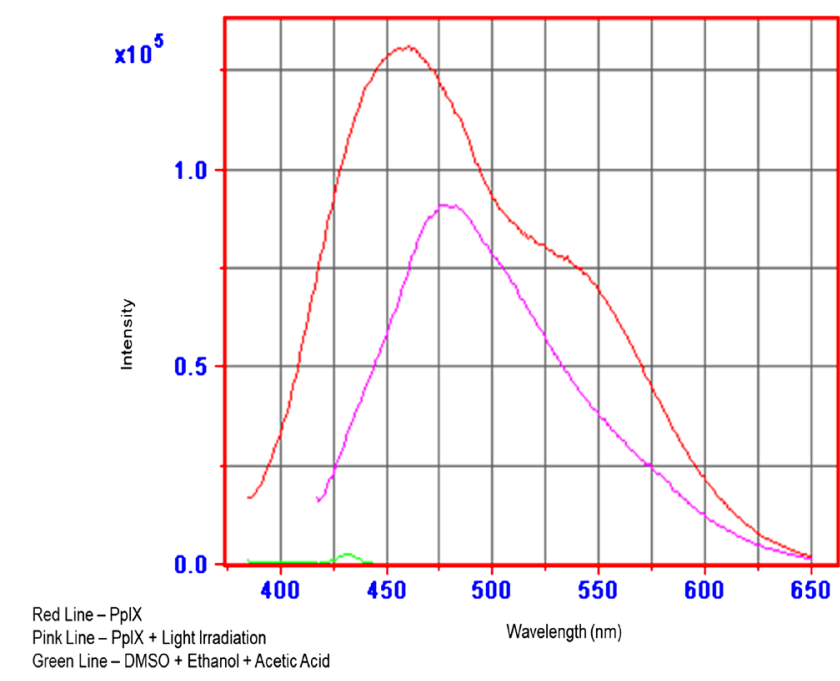

FIGURE 1 - Spectrofluorometry analysis of PpIX. The red line represents bacteria $+\partial$-ALA incubated for $13 \mathrm{~min}$. The presence of PpIX after the exogenous administration of $\partial$-ALA was demonstrated. The pink line represents bacteria $+\partial$-ALA + laser irradiation $\left(200 \mathrm{~J} / \mathrm{cm}^{2}\right)$. A decreased of the signal of PpXI after laser activation was shown. The results are the mean of the experiments. 


\section{Photosensibilitation of PpIX}

Bacterial samples were incubated with $\partial$-ALA, the precursor of PpIX. After the PpIX was identified by spectrofluorometry, the samples were irradiated with an argon laser at $510 \mathrm{~nm}$ (Leica Microsystems $\mathrm{GmbH}$, Mannheim, Germany) for $8 \mathrm{~min}, 33 \mathrm{sec}$ to reach a $200 \mathrm{~J} / \mathrm{cm}^{2}$ dose. Then, the samples were evaluated by spectrofluorometry to assess the signal of PpIX after irradiation. A decrease in the signal was found, (pink line), which could be interpreted as less availability of PpIX due to its photoactivation (Figure 1).

\section{Determination of the antibacterial effect of PpIX over planktonic E. faecalis}

The multilevel model included the follow terms: groups (G1, G2, G3 and G4), time and the interaction term for both. According to the data, G4 show a lower number of CFUs compared with G2 $(\mathrm{P}<0.001)$ and G3 $(\mathrm{P}=0.0167)$ at 0,24 and $72 \mathrm{~h}$. For $\mathrm{G} 4$ and $\mathrm{G} 1$ at 0,24 and 72 hours, there is no significant difference between groups ( $\mathrm{P}=0.9685)$, indicating that the $\delta$-ALA ( $40 \mu \mathrm{g}$ ) $\mathrm{mL}$ ) activated with the argon lase has an antibacterial effect similar to $5.25 \% \mathrm{NaOCl}$. For G2 and G3 at 0,24 and $72 \mathrm{~h}$, there is no significant difference between groups $(\mathrm{P}<0.001)$, indicating that the application of either $\delta$-ALA or laser alone has no antibacterial effect (Figures 2, 3).

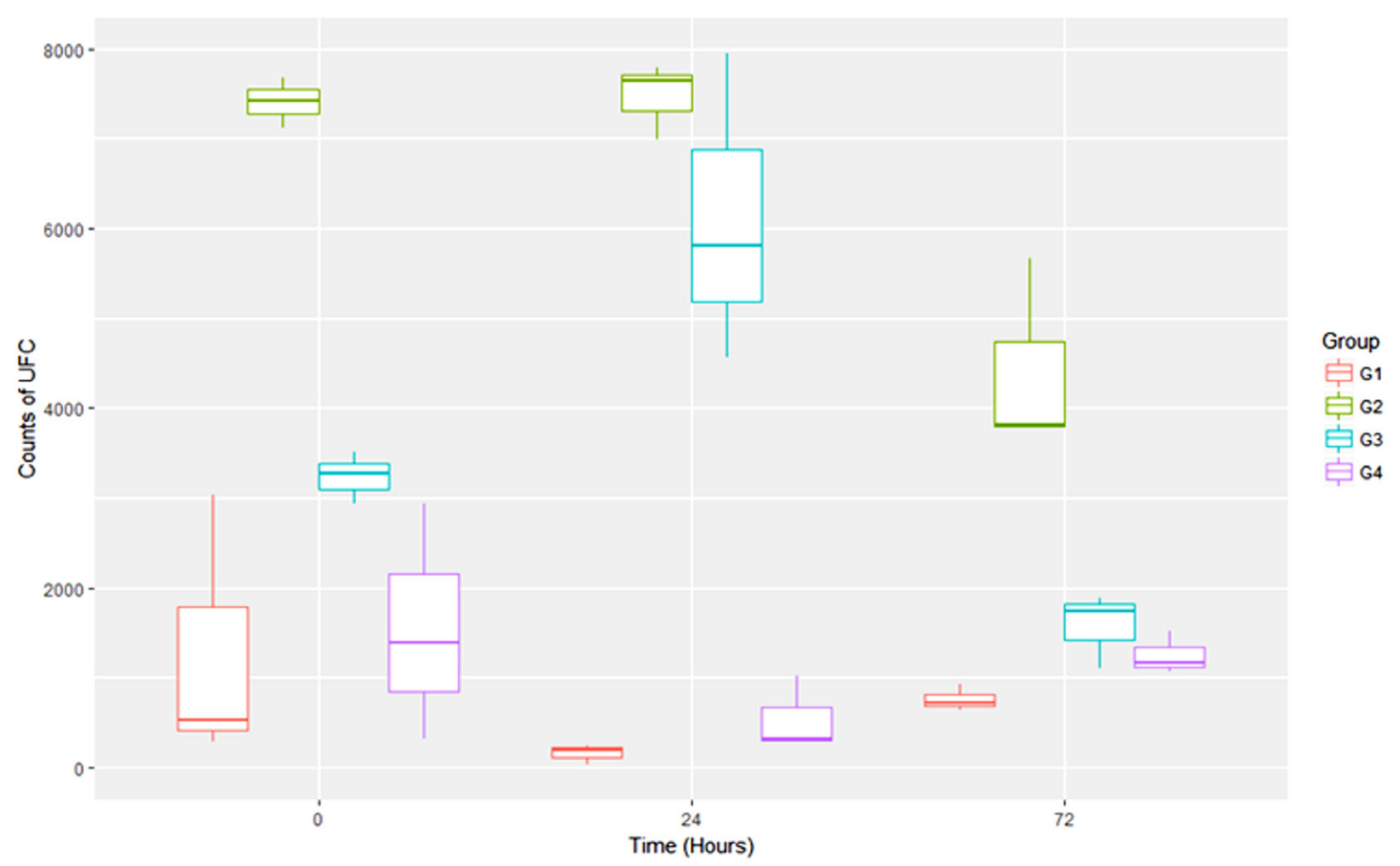

FIGURE 2 - Box-Plot: UFC vs Time for Group. Group 1 (G1), A positive control group treated with $800 \mu \mathrm{L}$ of thioglycolate + $200 \mu \mathrm{L}$ of $\mathrm{NaOCl} 5.25 \%$; group 2 (G2), $1 \mathrm{~mL}$ of thioglycolate + laser irradiation (8 min, $33 \mathrm{sec}$ ); group 3 (G3), $1 \mathrm{~mL} \delta$-ALA $(40 \mu \mathrm{g} / \mathrm{mL})$-thioglycolate solution; and Group 4 (G4), $1 \mathrm{~mL}$ of $\delta$-ALA $(80 \mu \mathrm{g} / \mathrm{mL})$-thioglycolate solution + laser irradiation $(8$ min, $33 \mathrm{sec}$ ). There was no significant difference between G4 and G1 at 0, 24 and $72 \mathrm{~h}$. There is a statically significant for G4 vs G2 and G3, at 0, 24 and 72 h. There was no significant difference between G2 and G3. 


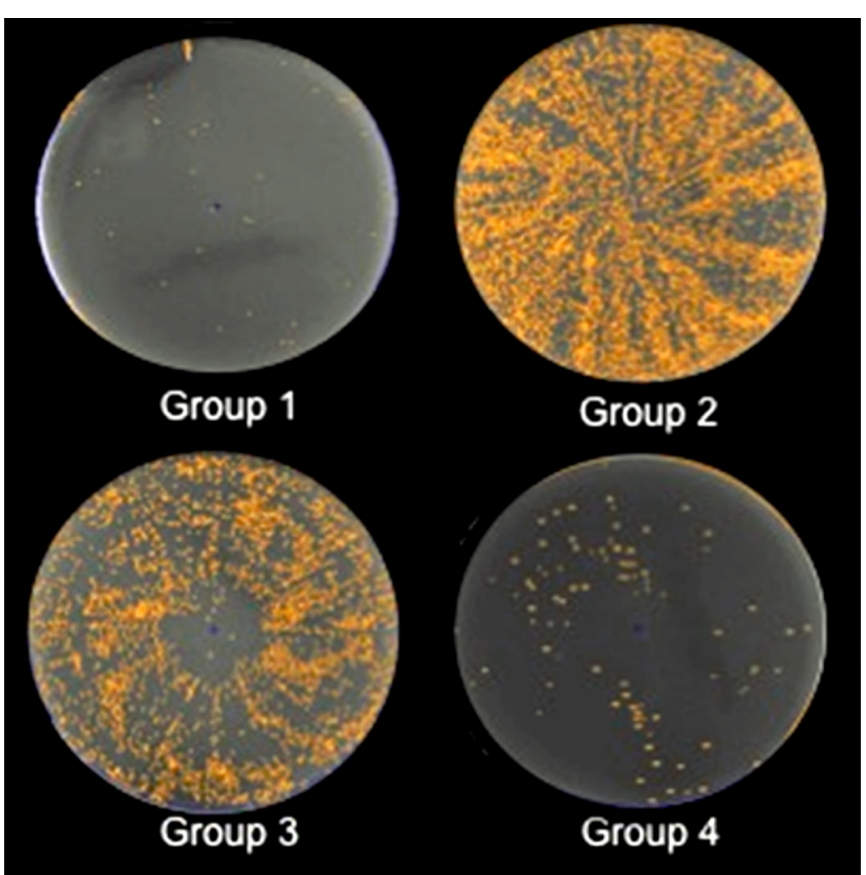

FIGURE 3 - The image shows the bacterial cell culture at 72 hrs. observed in a photodocument system (Bio-Rad of Quantity One). Group 1 (G1), a positive control group treated with $800 \mu \mathrm{L}$ of thioglycolate $+200 \mu \mathrm{L}$ of $\mathrm{NaOCl} 5.25 \%$; group 2 (G2), $1 \mathrm{~mL}$ of thioglycolate + laser irradiation ( $8 \mathrm{~min}$, $33 \mathrm{sec}$ ); group 3 (G3), $1 \mathrm{~mL} \delta$-ALA ( $40 \mu \mathrm{g} / \mathrm{mL})$-thioglycolate solution; and group 4 (G4), $1 \mathrm{~mL}$ of $\delta$-ALA $(80 \mu \mathrm{g} / \mathrm{mL})$ thioglycolate solution + laser irradiation ( $8 \mathrm{~min}, 33 \mathrm{sec}$ ). Yellow shows the UFCs of each of the groups, and there is a lower CFU amount in G4 compared to G2 and G3.

\section{Determination of the antibacterial effect of PpIX over E. faecalis biofilm}

The cell viability test evaluated by CTC of the biofilms treated with $\delta$-ALA $(80 \mu \mathrm{g} / \mathrm{mL})$ and irradiated with an argon laser, $510 \mathrm{~nm}, 200 \mathrm{~J} / \mathrm{cm}^{2}$ (group D), show a small number of bacteria compared with the groups not treated (group "b" and group "c"), demonstrating that the activation of PpIX by a laser has an antibacterial effect, even without biofilm disruption (Figure 4).
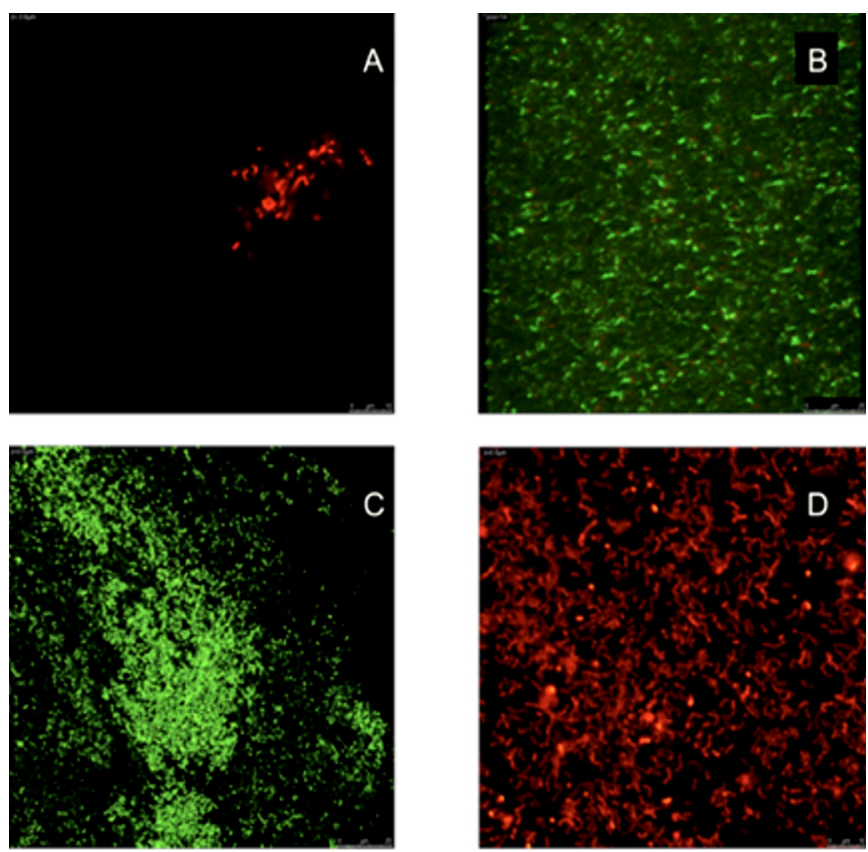

FIGURE 4 - LIVE/DEAD Test. Group “a” (GA), a positive control group treated with $800 \mu \mathrm{L}$ of thioglycolate +200 $\mu \mathrm{L}$ of $\mathrm{NaOCl} 5.25 \%$; group "b" (GB), $1 \mathrm{~mL}$ of thioglycolate + laser irradiation (8 min, $33 \mathrm{sec}$ ), group "c" (GC), $1 \mathrm{~mL}$ $\delta$-ALA $(80 \mu \mathrm{g} / \mathrm{mL})$-thioglycolate solution; group " $\mathrm{d}$ " (GD), $1 \mathrm{~mL}$ of $\delta$-ALA $(80 \mu \mathrm{g} / \mathrm{mL})$-thioglycolate solution $\left(5 \times 10^{7}\right.$ cells $\left./ \mathrm{mL}\right)+$ laser irradiation $(8 \mathrm{~min}, 33 \mathrm{sec})$. Group "a" show decomposition and an antibacterial effect on the biofilm treated with $\mathrm{NaOCl} 5.25 \%$. Group "b" and group "c" do not show antibacterial effects or decomposition of the biofilm. Group "d" shows an antibacterial effect without decomposition of biofilm when exogenously administered $\delta$-ALA and irradiated with an argon laser at $510 \mathrm{~nm}$ and $200 \mathrm{~J} / \mathrm{cm}^{2}$.

\section{DISCUSSION}

PDT is a clinical procedure that has emerged as a non-invasive therapy for the treatment of infections (Dai et al., 2012; Rajesh et al., 2011) and represents an alternative to conventional pharmacological therapies. This therapy is a promising strategy to eliminate pathogenic microorganisms, including Gram-positive and Gram-negative bacteria, viruses, yeasts and fungi (Rajesh et al., 2011; Sperandio, Huang, Hamblin, 2013), and its application could be particularly useful against resistant microorganisms or when traditional treatment does not completely eliminate microorganisms (Soukos et al., 2006). Additionally, it was shown that PDT not only kills the microorganism, but may also lead to the detoxification of endotoxins, 
such as lipopolysaccharides (Rajesh et al., 2011). Another advantage of PDT over traditional antibiotic treatments is that with PDT, is possible avoid the appearance of undesired drug-resistant bacteria strains (Sperandio, Huang, Hamblin, 2013).

In the present study, the antibacterial effect of PDT on E. faecalis in planktonic and biofilm forms was evaluated using $\delta$-ALA as a pre-photosensitizer in combination with an argon laser. The results obtained by spectrofluorometry verified that the $\delta$-ALA administered to the microorganism is metabolically transformed in PpIX. When the PpIX was irradiated by an argon laser, the amount of PpIX was reduced, thereby decreasing the intensity of PpIX, indicating that the PpIX was activated by laser irradiation. This outcome also corroborated the antibacterial effect on microorganisms in planktonic and biofilm forms, even without biofilm disruption, comparable with the effect of sodium hypochlorite $(\mathrm{NaOCl})$.

Biofilms on a variety of medical devices have been studied extensively over the past 25 years, and research on some of devices has demonstrated the susceptibility of most materials to microbial adherence and biofilm formation (Talsma, 2007). The use of $\delta$-ALA may become an alternative or complement to solve this clinical issue of medical devices, even without biofilm mechanical disruption.

The results obtained in this study are consistent with data reported previously about the use of PDT to treat bacterial infections (Kharkwal et al., 2011), which concluded that although PDT has some limitations that need to be overcome, it has the potential to be used to treat a number of infectious diseases.

The present results are similar to data obtained by López-Jiménez et al. (2015), who evaluated the effect of toluidine blue and methylene blue as PS agents in combination with a light-emitting diode, at $628 \mathrm{~nm}, 30$ J, on a biofilm of an ATCC 29212 of E. faecalis. They reported that this protocol has effective antibacterial activity, and they also evaluated the surface of the biofilm treated with PDT by atomic force microscopy, reporting that the topography of the biofilm was modified after PDT treatment with an increase in the roughness of the surface of the biofilm. This effect could be beneficial because this could expose the bacteria of biofilms to the PS agent and light, producing a better antibacterial effect. It is important to highlight that toluidine blue and methylene do not a have wide range of activation such as PpIX, limiting its application to certain tissues.
In this study, a dose of $200 \mathrm{~J} / \mathrm{cm}^{2}$ was used based on the results reported by Li et al. (2013) who evaluated the use of $\delta$-ALA on biofilm of methicillin-resistant strains (S. aureus and S. epidermidis), and reported that $\delta$-ALA was absorbed and converted to PpIX by both types of bacteria strains. After the samples were irradiated with a semiconductor laser at different potencies $(0,100$, 200 , and $300 \mathrm{~J} / \mathrm{cm}^{2}$ ), an antibacterial effect was shown directly proportional to the dose of $\mathrm{J} / \mathrm{cm}^{2}$ administered with a max response at $200-300 \mathrm{~J} / \mathrm{cm}^{2}$. The present results are consistent with these data, showing the presence of PpIX after the exogenous administration of $\delta$-ALA and a reduction in the amount of PpIX after laser irradiation. The results also showed an antibacterial effect at a laser dose of $200 \mathrm{~J} / \mathrm{cm}^{2}$.

Fotinos et al. (2008) demonstrated the ability to inactivate Gram-positive (methicillin-resistant $S$. aureus) and Gram-negative (two E. coli strains and a $P$. aeruginosa strain) bacteria by photodynamic therapy after incubation with $\delta$-ALA. An inactivation rate of $99.9 \%$ was reported for both $E$. coli strains and $P$. aeruginosa. $S$. aureus was significantly more sensitive to $\delta$-ALA porphyrins, with a survival rate even lower than the Gram-negative strains, demonstrating the antibacterial effect of porphyrins metabolized from $\delta$-ALA on Gram-positive and Gram-negative bacteria. Similar results were obtained in this study, in which Gram-positive bacteria (E. faecalis) in planktonic and biofilm forms were used, demonstrating that activation of PpIX by an argon laser has an antibacterial effect even in the presence of a biofilm.

As previously discussed, the microorganisms in a biofilm are more resistant to antimicrobials (Balcázar, Subirats, Borrego, 2015; Donelli, 2014; Donlan, 2011; Li et al., 2013; López-Jiménez et al., 2015), and the most common methods to treat and eliminate biofilms are mechanical disruption and antimicrobial therapy; however, the efficacy of these strategies is limited (López-Jiménez et al., 2015; Rajesh et al., 2011). In this study, it was shown that the disruption of the biofilm is not necessary to inactivate the bacteria with the use of exogenously administered $\delta$-ALA to produce intracellular PpIX. Barra et al. (2015) evaluated the application of $\delta$-ALA and light-emitting diode irradiation on bacteria biofilms ( $S$. aureus, $S$. epidermidis, and $S$. haemolyticus) using a viability cell test. It was shown that the viability of the three bacteria in the biofilm was reduced to $20 \%$ of the original values, but it was necessary to increase the light dose administered to 
reach adequate bacterial inactivation, indicating that the light dose is a critical factor to achieve the desire effect. In the present study, it was necessary to increase the concentration of $\partial$-ALA to achieve an antibacterial effect on the biofilm. This may be because the biofilm acts a semi-barrier that limits the penetration of $\partial$-ALA to the bacteria cells.

One of the main disadvantages related to the clinical application of PDT is that the PS agents have specific absorption peaks, limiting the use of certain types of light sources, and in some cases the wavelength used cannot penetrate deep tissues. With $\delta$-ALA as a pre-photosensitizer, it is possible to overcome this clinical situation because PpIX has different absorption peaks (410 nm, $510 \mathrm{~nm}, 545 \mathrm{~nm}, 580 \mathrm{~nm}$, and $635 \mathrm{~nm}$ ) (Hino et al., 2013), offering the ability to be activated by different sources of light at different wavelengths, thus making it useful to treat bacterial infections on dermis and epidermis tissues (Sperandio, Huang, Hamblin, 2013; Wachowska et al., 2011). Furthermore, $\delta$-ALA has several advantages over other photosensitizers. It has a rapid metabolism and high selectivity for malignant lesions (Wachowska et al., 2011) and bacteria (Barra et al., 2015). In this study, all treatment groups incubated with $\delta$-ALA show an antibacterial effect, including the G3 ( $\delta$-ALA, without laser irradiation). Finally, the rapid systemic clearance of ALA-induced PpIX within $24 \mathrm{~h}$ eliminates prolonged photosensitivity and allows treatment to be repeated at regular intervals without cumulative effects and the risk of damage to tissues (Wachowska et al., 2011).

The production and accumulation of PpIX induced by an exogenously administered $\delta$-ALA on E. faecalis biofilms was shown. The photoactivation of PpIX with an argon laser produced an antibacterial effect even without disruption of the biofilm. From our results, this therapy could become an alternative to conventional mechanical disruption or pharmacological therapies for the treatment of bacterial infections related to the presence of biofilm on biomedical devices that cannot be used treated with sodium hypochlorite. Exhaustive in vitro and in vivo studies are required to fully support the use of this methodology as an alternative or complementary method to treat bacterial infections.

\section{ACKNOWLEDGMENTS}

The authors would like to thank to CONACyT grants 514260 and 599447 to Abraham Muñoz and
Vicente Esparza-Villalpando. This CONACYT grant has not relation with the conduct of the research and/ or preparation of the article. This work was supported partially by the PFCE-UASLP, 2018 grant.

\section{COMPLIANCE WITH ETHICAL STANDARDS}

All actions performed in studies including human participants were in accordance with the 1964 Helsinki declaration and with the ethical standards of the institutional and/or national research committee.

\section{ETHICAL APPROVAL}

This study was approved by the Institutional Research Ethic Committee of the Faculty of Dentistry, Sinaloa University with the register code CEYS 2011-11.

\section{CONFLICT OF INTEREST}

The authors declare that they have no competing interests.

\section{REFERENCES}

Balcázar JL, Subirats J, Borrego CM. The role of biofilms as environmental reservoirs of antibiotic resistance. Front Microbiol. 2015;6:1-9.

Barra F, Roscetto E, Soriano AA, Vollaro A, Postiglione I, Pierantoni MG, et al. Photodynamic and antibiotic therapy in combination to fight biofilms and resistant surface bacterial infections. Int J Mol Sci. 2015;16(9):20417-20430.

Breskey JD, Lacey SE, Vesper BJ, Paradise WA, Radosevich JA, Colvard MD. Photodynamic therapy: occupational hazards and preventative recommendations for clinical administration by healthcare providers. Photomed Laser Surg. 2013;31(8):398-407.

Dai T, Fuchs BB, Coleman JJ, Prates RA, Astrakas C, St. Denis TG, et al. Concepts and principles of photodynamic therapy as an alternative antifungal discovery platform. Front Microbiol. 2012;3(3):1-16.

Darouiche RO. Device-associated infections: a macroproblem that starts with microadherence. Clin Infect Diseases. 2001;33(9):1567-1572.

Djordjevic D, Wiedmann M, McLandsborough LA. Microtiter plate assay for assessment of Listeria monocytogenes biofilm formation. Appl Environ Microbiol. 2002;68(6):2950-2958. 
5-aminolevulinic acid photoactivated over planktonic and biofilm forms of Enterococcus faecalis as a pharmacological therapy alternative

Dobson J, Wilson M. Sensitization of oral bacteria in biofilms to killing by light from a low-power laser. Arch Oral Biol. 1992;37(11):883-887.

Donelli G. Microbial biofilms: methods and protocols, methods in molecular biology. 2014 Rome, Italy: Human Press; 2014.

Donlan RM. Biofilm elimination on intravascular catheters: Important considerations for the infectious disease practitioner. Clin Infect Dis. 2011;52(8):1038-1045.

Fotinos N, Convert M, Piffaretti J-C, Gurny R, Lange $\mathrm{N}$. Effects on gram-negative and gram-positive bacteria mediated by 5 -aminolevulinic acid and 5 -aminolevulinic acid derivatives. Antimicrob Agents Chemother. 2008;52(4): 1366-1373.

Gilmore MS, Clewell DB, Ike Y, Shankar N. Enterococci: from commensals to leading causes of drug resistant infection. Massachusetts Eye and Ear Infirmary. Boston, Massachusetts; 2014.

Hino H, Murayama Y, Nakanishi M, Inoue K, Nakajima M, Otsuji E. 5-Aminolevulinic acid-mediated photodynamic therapy using light-emitting diodes of different wavelengths in a mouse model of peritoneally disseminated gastric cancer. J Surg Res. 2013;185(1):119-126.

Homayoni H, Jiang K, Zou X, Hossu M, Rashidi LH, Chen W. Enhancement of protoporphyrin IX performance in aqueous solutions for photodynamic therapy. Photodiagnosis Photodyn Ther. 2015;12(2):258-266.

Kaplan JB, Ragunath C, Velliyagounder K, Fine DH, Ramasubbu N. Enzymatic detachment of Staphylococcus epidermidis biofilms. Antimicrob Agents Chemother. 2004;48(7):2633-2636.

Kharkwal GB, Sharma SK, Huang Y, Dai T, Hamblin MR. Photodynamic therapy for infections: Clinical applications. Lasers Surg Med. 2011;43(7):755-767.

Li X, Guo H, Tian Q, Zheng G, Hu Y, Fu Y, Tan H. Effects of 5-aminolevulinic acid-mediated photodynamic therapy on antibiotic-resistant staphylococcal biofilm: an in vitro study. J Surg Res. 2013;184(2):1013-1021.
López-Jiménez L, Fusté E, Martínez-Garriga B, ArnabatDomínguez J, Vinuesa T, Viñas M. Effects of photodynamic therapy on Enterococcus faecalis biofilms. Lasers Med Sci. 2015;30(5):1519-1526.

Malik Z, Lugaci H. Destruction of erythroleukaemic cells by photoactivation of endogenous porphyrins. Brit J Cancer. 1987;56(5):589-595.

Manzur A, González AM, Pozos A, Silva-Herzog D, Friedman S. Bacterial quantification in teeth with apical periodontitis related to instrumentation and different intracanal medications: a randomized clinical trial. J Endod. 2007;33(2):114-118.

Pagonis TC, Chen J, Fontana CR, Ruggiero K, Song X, Foschi F, et al. Nanoparticle-based endodontic antimicrobial photodynamic therapy. J Endod. 2010;36(2):322-328.

Rajesh S, Koshi E, Mohan A, Philip K. Antimicrobial photodynamic therapy: An overview. J Indian Soc Periodontol. 2011;15(4):323-327.

Sasaki K, Tanakay T, Nagai S, Nishio N. Effect of culture Ph on the extracellular production of 5 -aminolevulinic acid by rhodobacter sphaeroides from volatile fatty acids. Biotechnol Lett. 1993;15(8):859-864.

Soukos NS, Chen PSY, Morris JT, Ruggiero K, Abernethy $\mathrm{AD}$, Som S, et al. Photodynamic therapy for endodontic disinfection. J Endod. 2006;32(10):979-984.

Sperandio FF, Huang Y-Y, Hamblin MR. Antimicrobial Photodynamic therapy to kill gram-negative bacteria. Recent Pat Antiinfect Drug Discov. 2013;8(2):108-120.

Talsma S. Biofilms on medical devices. Home Healthcare Nurse. 2007;25(9):589-594.

Wachowska M, Muchowicz A, Firczuk M, Gabrysiak M, Winiarska M, Wańczyk M,et al. Aminolevulinic acid (ALA) as a prodrug in photodynamic therapy of cancer. Molecules. 2011;16(5):4140-4164.

Zaw MT, Yuthika H, Lakshman P. In vitro biofilm formation of Candida albicans and non-albicans Candida species under dynamic and anaerobic conditions. Arch Oral Biol. 2007;52(8):761-767.

Received for publication on $06^{\text {th }}$ July 2018 Accepted for publication on $17^{\text {th }}$ October 2018 